\title{
O PAPEL DO ACESSO À JUSTIÇA E DAS PRÁTICAS CIDADÃS PARA A COMPREENSÃO DA JUDICIALIZAÇÃO DA POLÍTICA NO BRASIL
}

\author{
THE ROLE OF ACCESS TO JUSTICE AND CITIZEN PRACTICES TO \\ UNDERSTAND THE JUDICIALIZATION OF POLITICS IN BRAZIL
}

\author{
Edith Maria Barbosa Ramos ${ }^{1}$ \\ Jaqueline Prazeres de Sena ${ }^{2}$ \\ Rossana Barros Pinheiro ${ }^{3}$
}

\section{RESUMO}

Ante o aumento do fenômeno judicialização da política no Brasil, caracterizada pela interferência do poder judiciário em searas de atuação dos poderes Executivo e Legislativo, observa-se o surgimento de questionamentos quanto ao papel efetivo do acesso à justiça e aprofundamento da cidadania para compreensão desse fenômeno. Nessa perspectiva, a judicialização da política é consideravelmente alimentada por outros elementos como o uso dos tribunais por grupos de interesse, bem como o manejo de ações constitucionais por oposições políticas como forma de obstaculizar as decisões majoritárias. Assim, a presente pesquisa objetivou possibilitar a compreensão mais clara da judicialização e suas relações efetivas com o aumento do acesso à justiça e amadurecimento dos vínculos de cidadania. Como metodologia, realizou-se abordagem qualitativa, devido o vínculo essencial existente entre o material em estudo e o tema em questão. No que diz respeito aos procedimentos técnicos, utilizou-se a pesquisa bibliográfica e documental.

Palavras-Chave: Judicialização da Política; Acesso à Justiça; Cidadania; Democracia; Poder Judiciário.

\footnotetext{
${ }^{1}$ Pós-Doutora em Direito Sanitário pela Fundação Oswaldo Cruz - FIOCRUZ/Brasília/DF. Doutora em Políticas Públicas pela Universidade Federal do Maranhão. Mestre em Direito pela Universidade Federal de Minas Gerais. Graduada em Direito pela Universidade Federal do Maranhão. Professora do Departamento de Direito e do Mestrado em Direito e Instituições do Sistema de Justiça da Universidade Federal do Maranhão. Coordenadora do Núcleo de Estudos em Direito Sanitário (NEDISA/UFMA). Professora e Pesquisadora da Universidade CEUMA. Professora do IMEC. Membro Convidado da Rede Ibero-Americana de Direito Sanitário. Presidente da Comissão de Bioética e Biodireito do Conselho Seccional da OAB/MA. Universidade Federal do Maranhão - UFMA; Universidade CEUMA - Brasil. Lattes: http://lattes.cnpq.br/7085054421011701 $\quad$ E-mail: edithramosadv@yahoo.com.br

${ }^{2}$ Doutoranda em Filosofia pela Universidade Estadual do Rio de Janeiro. Mestre em Direito pela Universidade Federal de Minas Gerais (2005). Bacharel em Direito pela Universidade Federal do Maranhão. Professora da Universidade Ceuma. Participa como Pesquisadora do Núcleo de Estudos em Direito Sanitário. Universidade CEUMA; Instituto Maranhense de Ensino e Cultura - IMEC - Brasil. Lattes: http://lattes.cnpq.br/0983674249152352 E-mail: edithramosadv@yahoo.com.br

${ }^{3}$ Mestre em Direito e Instituições do Sistema de Justiça pelo Programa de Pós-Graduação em Direito e Instituições do Sistema de Justiça da Universidade Federal do Maranhão (2018). Graduada em Direito pela Universidade Federal do Maranhão (2016). Advogada. Técnica em Design de Produto pelo Instituto Federal de Educação, Ciência e Tecnologia do Maranhão-IFMA (2007/2010). Universidade Federal do Maranhão - UFMA - Brasil. Lattes: http://lattes.cnpq.br/6488993957869669 E-mail: edithramosadv@yahoo.com.br
} 


\begin{abstract}
Faced with the increase in the judicialization of politics phenomenon in Brazil, characterized by the interference of the judiciary in fields of action of the Executive and Legislative powers, there is the emergence of questions about the effective role of access to justice and the deepening of citizenship to understand this phenomenon. . From this perspective, the judicialization of politics is considerably fueled by other elements such as the use of courts by interest groups, as well as the handling of constitutional actions by political oppositions as a way of hindering majority decisions. Thus, the present research aimed to enable a clearer understanding of judicialization and its effective relationships with increasing access to justice and maturing citizenship bonds. As a methodology, a qualitative approach was performed due to the essential link existing between the material under study and the theme in question. Regarding the technical procedures, the bibliographic and documentary research was used.
\end{abstract}

Key words: Judicialization of the Policy; Access to justice; Citizenship; Democracy; Judicial power.

\title{
INTRODUÇÃO
}

Caracterizada pela ingerência significativa do poder judiciário em temáticas de cunho claramente político, bem como o exercício de funções em limites que correspondem ao âmbito de atuação dos demais poderes, a judicialialização da política tem ocorrido associada a diversas variáveis, observadas em modo e intensidade diferenciadas conforme as peculiaridades de cada país

Nessa discussão, são condições políticas favoráveis para o aparecimento desse fenômeno o déficit democrático oriundo da crise de legitimidade política, implantação dos sistemas democráticos em toda América Latina, emergência de práticas cidadãs de enfrentamento à corrupção, a catalogação de variadas categorias de direitos nas Constituições modernas, entre outros, enquanto são condições institucionais a complexidade do aparato administrativo e a magnitude de suas funções

Nessa discussão, o processo de judicialização mantém relações diretas com a descrença popular ante a efetividade política dos poderes Legislativo e Executivo, que conduz à formação de expectativas no sentido que o poder Judiciário é essencialmente a instância mais apropriada para a resolução de demandas políticas de alcance público e particular, como destacaram Ramos e Diniz (2017).

Considerando tal complexidade observada no contexto brasileiro, o texto da Constituição e 1988 manteve o escopo de assegurar a participação cidadã nos processos 
decisórios e nos seus resultados, conferindo legitimidade especialmente à atuação jurisdicional. Essa tendência se deve à conjuntura de protagonismo da sociedade civil na vida política à época de implantação da assembleia constituinte.

Tais mecanismos de interação entre sociedade civil e Poder Judiciário devem ser interpretados levando-se em consideração uma conjuntura política que ressignificou profundamente a natureza do referido poder e de suas funções. Assumindo uma posição de centralidade no desenho institucional brasileiro, o Judiciário tornou-se gradativamente um dos protagonistas da vida política.

Todas essas transformações se deram à luz de sensíveis reestruturações nas teorias constitucionais quanto ao influxo da Constituição sobre a transformação da realidade fática e quanto à percepção dos papéis jurisdicionais no Brasil, o que ocorreu sob influência de movimentos históricos, políticos e doutrinários nacionais e internacionais.

Diante de todo o exposto, poder-se-ia pensar que o aprofundamento do processo de judicialização da política estaria faticamente inter-relacionado com o amadurecimento do conceito de cidadania, acesso à justiça e ampliação dessas nos ambientes institucionais decisórios.

No entanto, essa percepção revela-se equivocada à medida que ainda se observa uma significativa distância entre o Poder Judiciário e o povo, bem como a fragilidade dos laços entre esses, barreiras materializadas nas dificuldades de acesso popular ao referido poder, que ainda subsistem, bem como na centralidade de outros elementos, como o uso dos tribunais pelos grupos de interesse, no núcleo dos processos de judicialização.

Assim, a judicialização da política é um fenômeno nutrido especialmente pelos interesses econômicos e sociais dominantes, capazes de conformar a natureza do processo político, o que pode ser constatado até mesmo na expansão dos direitos, mais atribuída à organização das lutas sociais e dos grupos de interesse do que ao altruísmo das autoridades ante os clamores populares.

Diante de todo o exposto, tornam-se necessários estudos no sentido de possibilitar a compreensão mais clara do peso relativo ao elemento cidadania nos processos de judicialização, de modo a se desmistificar os entendimentos ingênuos que obstam o maior esclarecimento da judicialização enquanto fenômeno social recorrente.

Desse modo, o presente estudo objetivou lançar bases para compreensão do peso conferido à cidadania e ao acesso à justiça na conjuntura da judicialização da política, utilizando para tanto pesquisas teóricas e empíricas. Como metodologia, realizou-se abordagem 
qualitativa, devido o vínculo essencial existente entre o material em estudo e o tema em questão. Segundo Gustin (2013) a pesquisa com abordagem qualitativa estuda os dados buscando seu significado, tendo como base a forma como se percebe o fenômeno da judicialização da política dentro do contexto do Estado brasileiro. Assim, ao utilizar a descrição qualitativa procura-se analisar não só os aspectos aparentes do fenômeno, como também seus aspectos formadores, buscando explicar sua origem, relações e mudanças, e tentando intuir as consequências.

A pesquisa, quanto aos objetivos, foi desenvolvida de forma a buscar na bibliografia disponível o estado da arte da relação entre a judicialização da política, a separação de poderes e a ideia de cidadania e acesso à justiça no Brasil. Para Gustin (2013, p 24)

A pesquisa qualitativa tem o ambiente natural como fonte direta de dados e o pesquisador como seu principal instrumento. Segundo os autores, a pesquisa qualitativa supõe o contato direto e prolongado do pesquisador com o ambiente e a situação que está sendo investigada via de regra, por meio do trabalho intensivo.

No que diz respeito aos procedimentos técnicos, utilizou-se a pesquisa bibliográfica e documental. Gustin (2013, p. 40) destaca que a pesquisa bibliográfica, em suma, é todo trabalho científico, porquanto toda pesquisa deve ter o apoio e o embasamento na pesquisa bibliográfica para que não se desperdice tempo com um problema que já foi solucionado e possa chegar a conclusões inovadoras.

Portanto, resta claro que a pesquisa bibliográfica não é uma simples catalogação de tudo o que já foi escrito a respeito do tema, mas sim uma busca minuciosa de informações que se possa analisar de forma profunda o problema proposto, de modo que se chegue a uma resposta inovadora para o tema, mesmo que não seja uma resposta conclusiva, mas que sirva como meio para levar o leitor à refletir sobre a temática proposta.

Por seu turno, a análise documental é indispensável na medida em que é realizada a partir de documentos, contemporâneos ou retrospectivos, considerados cientificamente autênticos. Desta feita, a análise documental constitui uma técnica importante na pesquisa qualitativa, seja complementando informações obtidas por outras técnicas, seja desvelando aspectos novos de um tema ou problema (LUDKE; ANDRÉ, 1986).

\section{APONTAMENTOS SOBRE O PROCESSO DE JUDICALIZAÇÃO DA POLÍTICA NO BRASIL}

A consolidação do sistema capitalista, acompanhado da deflagração mais intensa dos efeitos do processo de globalização constituíram cenário político para a abertura democrática 
em grande parte dos países latino-americanos, onde se observa a predominância das ideologias neoliberais e a expansão do âmbito de atuação do poder judiciário.

Caracterizada pela ingerência significativa do referido poder em temáticas de cunho claramente político, bem como o exercício de funções em limites que correspondem aos demais poderes, a judicialialização da política tem ocorrido associada a diversas variáveis, observadas, cujo modo e intensidade se diferenciam conforme as peculiaridades de cada país. Barbosa considera que:

É através desta consideração que o Poder Judiciário passa a ter participação significativa no controle das atividades estatais, denotando um processo nominado pelos cientistas políticos contemporâneos pelo termo judicialização da política, caracterizado quando o Judiciário passa a tratar diretamente de assuntos estranhos à sua competência, ou seja, que deveriam ser, aprioristicamente, enfrentados pelo Poder Executivo ou mesmo disciplinados pelo Poder Legislativo, ou quando um "modus operandi" tipicamente judicial passa a ser incorporado por outras áreas, utilizando-se destas técnicas e procedimentos judiciais (BARBOSA, 2015, p. 151).

Pontuando as principais condições que favorecem consideravelmente a emergência do processo de judicialização, os estudiosos costumam classificá-las conforme a natureza institucional, relacionadas com a própria estrutura organizacional de cada país considerado, ou política, relativas à conjuntura observada.

Nessa discussão, são condições políticas o déficit democrático oriundo da crise de legitimidade política, implantação dos sistemas democráticos em toda América Latina, emergência de práticas cidadãs de enfrentamento à corrupção, a catalogação de variadas categorias de direitos nas Constituições modernas, entre outros, enquanto são condições institucionais a complexidade do aparato administrativo e a magnitude de suas funções.

Considerando todas essas condições propícias para a judicalização da política, o Poder Judiciário tem alcançado índices consideráveis de visibilidade, haja vista a tomada de decisões políticas não obstante o arcabouço constitucional tradicional que o relaciona às questões de natureza essencialmente jurídica, como bem observou Fontoura (2015, p. 1422). Barroso destaca que:

Nos últimos vinte anos, o Judiciário ingressou na paisagem institucional brasileira. Já não passa despercebido nem é visto com indiferença ou distanciamento. Há mais de uma razão para esse fenômeno. A ascensão do Poder Judiciário se deve, em primeiro lugar, à reconstitucionalização do país: recuperadas as liberdades democráticas e as garantias da magistratura, juízes e tribunais deixaram de ser um departamento técnico especializado e passaram a desempenhar um papel político, dividindo espaço com o Legislativo e o Executivo (BARROSO, 2008, p. 212). 
Aprofundando com acuidade a temática da falta de identidade institucional entre cidadãos e poderes da República, no contexto de apatia política, Rolón (2005) pontua que o colapso da legitimidade, em uma conjuntura de corrupção e escândalos eleitorais, tem motivado a atuação das cortes no processo de elaboração das leis e a expansão da interpretação jurisdicional de conflitos sociais.

$\mathrm{O}$ autor ainda acrescenta que os avanços tecnológicos, processos de urbanização e aumento da complexidade do aparato estatal tem suscitado a preocupação no sentido de dar respostas a debilidade institucional e insegurança dos cidadãos. Maciel e Koerner consideram que:

\begin{abstract}
Os juristas usam o termo judicialização para se referirem à obrigação legal de que um determinado tema seja apreciado judicialmente. Próximo a esse sentido, mas já com caráter normativo, afirma-se que judicialização é o ingresso em juízo de determinada causa, que indicaria certa preferência do autor por esse tipo de via. Refere-se a decisões particulares de tribunais, cujo conteúdo o analista consideraria político, ou referente a decisões privadas dos cidadãos (como questões de família). Decisões judiciais particulares poderiam ser sujeitas a escrutínio e seu conteúdo poderia ser avaliado como "grau de judicialização". A expressão é usada neste sentido mesmo para decisões que não são propriamente judiciais como no caso da verticalização das coligações políticas decidida pelo TSE. Ou refere-se à situação excepcional de maior número de conflitos políticos no Judiciário, própria aos períodos de eleições (MACIEL; KOERNER, 2002, p. 115).
\end{abstract}

Nessa discussão, o processo de judicialização mantém relações diretas com a descrença popular ante a efetividade política dos poderes Legislativo e Executivo, que conduz à formação de expectativas no sentido que o Poder Judiciário é essencialmente a instância mais apropriada para a resolução de demandas políticas de alcance público e particular.

Aprofundando melhor a discussão em torno das deficiências estruturais da América Latina que fazem parte do contexto de maior participação do poder judiciário na vida política, Barbosa e Fernandez (2015) pontuam que nessa região são verificados déficits consideráveis em várias áreas envolvendo direitos sociais, especialmente relacionados à educação, saúde e lazer.

Os autores observam ainda a situação específica do Brasil, onde são observados déficits gritantes envolvendo a proteção direito à vida, integridade, liberdade, segurança, alimentação e saúde como bem observou Motta (2012, p. 220). Nessa perspectiva, as ações de natureza cidadã, como ação civil pública e ação popular assumem posição privilegiada entre os instrumentos de reivindicação popular ante as instituições do sistema de justiça. 
Continuando esse debate acerca da judicialização da política no Brasil, Brandão (2013) observa que o Supremo Tribunal Federal tem decidido gradativamente questões de natureza eminentemente política, destoando visivelmente dos princípios organizacionais estabelecidos na Constituição Federal. Mais uma vez, Barroso destaca que:

São cada vez mais presentes estudos jurídicos que apontam para um panorama de atuação judicial efetiva na vida social, ou seja, na discussão de questões de grande repercussão para a vida em sociedade. No contexto brasileiro, os Tribunais parecem ter sido alçados à uma posição de defesa sistêmica de direitos sociais básicos, alçados pela Constituição Federal de 1988 no grande rol, em constante evolução, de direitos e garantias fundamentais. Diante da relativa inoperância dos demais Poderes Públicos, o Poder Judiciário tem assumido papel relevante para as democracias contemporâneas, sendo considerado como o grande redentor das questões públicas e privadas, especialmente no que concerne à maximização das políticas públicas sociais (BARROSO, 2008, p. 149).

No tocante à interferência do Poder Judiciário em matérias envolvendo políticas públicas, por exemplo, aquele tem afirmado a urgência na concretização das políticas sociais e a relação dessa com o princípio da dignidade da pessoa humana, não obstante os limites contingenciais que legitimariam uma omissão dos demais poderes.

Considerando que o processo de judicialização, observado gradativamente em todas as dimensões da vida social, está condicionado a motivações variáveis conforme a realidade considerada, existem elementos observados de modo constante como por exemplo o pluralismo político, as dimensões do controle de constitucionalidade e a escolha pelo regime democrático.

Aprofundando melhor esse debate, Barbosa e Fernandez (2015) observam a importância de condições como a democracia e o pluralismo político, elementos que constituem núcleo essencial para o aumento dos direitos assegurados no texto constitucional e a extensão das funções judiciárias atinentes à sua preservação. Implicando os mesmos reflexos, o federalismo e a separação de poderes acarretam a maior divisão vertical e horizontal do pode político, havendo a maior possibilidade de conflitos e sua consequente inclusão nas pautas jurisdicionais.

Somadas a essas condições, acrescenta-se ainda a perda de confiança popular nos agentes políticos e nas instituições majoritárias e as fortes esperanças depositadas no Judiciário, em um contexto de constituições programáticas que estabelecem catálogos extensos de direitos garantidos mediante a intervenção jurisdicional. Barroso destaca que:

Uma segunda razão foi o aumento da demanda por justiça na sociedade brasileira. De fato, sob a Constituição de 1988, houve uma revitalização da cidadania e uma maior conscientização das pessoas em relação à proteção de seus interesses. Além disso, o texto constitucional criou novos direitos e novas ações, bem como ampliou as hipóteses de legitimação extraordinária e de tutela coletiva. Nesse 
ambiente, juízes e tribunais passaram a desempenhar um papel simbólico importante no imaginário coletivo (BARROSO, 2008, p. 41).

Aprofundando a discussão em torno da expansão do poder judiciário, Carvalho (2004) pontua que esse fenômeno ganhou corpo especialmente no fim do século passado, quando parte considerável dos países ocidentais democráticos adotou os Tribunais Constitucionais como instrumentos de controle dos demais poderes, o que implicou em consequências diretas na implementação de políticas públicas.

Nessa perspectiva, a negociação política com o Parlamento deve acontecer de forma a manter a preservação semântica do texto constitucional, desafio que permite a ocupação de um lócus decisório privilegiado pelo poder judiciário no tocante aos processos decisórios que envolvem o controle dos demais poderes (CARVALHO, 2004).

Investigando os contornos do processo de judicialização, Ernani pontua que esse não deve ser visualizado tão somente como o aumento puro e simples do número de processos movidos ante a instância judiciária, mas pela modificação da lei os dos demais atos dos demais poderes, identificando assim a necessidade de critérios para uma melhor compreensão desse fenômeno. Carvalho assinala que:

Mesmo se considerarmos a hipótese de que a taxa de julgamento é satisfatória, o que garante que a decisão proferida foi assertiva? Ou que o juiz escolheu intervir? $\mathrm{O}$ aumento da demanda judicial não diz se o Judiciário está ou não intervindo. Ora, se o aumento das ações não é suficiente para caracterizar o processo de judicialização, o que fazer? Já foi possível perceber que temos um problema para conceituar, caracterizar e medir o processo de judicialização da política (CARVALHO, 2004, p. 122).

O autor observa ainda que de forma automática as causas da judicialização são frequentemente associadas ao aumento da litigância processual, havendo a necessidade de inclusão de novos critérios para abordagem desse problema.

Em síntese, corroborando esse raciocínio, Maciel (2002) aponta que o retrato otimista relacionado à atuação das instituições em tempos de judicialização deve ser relativizado, haja vista a necessidade de desenvolvimento de pesquisas empíricas enfocando as relações interinstitucionais travadas entre o conteúdo das decisões e os sujeitos, considerados com suas expectativas. 


\section{JUDICIALIZAÇÃO, ACESSO E JUSTIÇA E CIDADANIA}

O escopo de assegurar a participação cidadã nos processos decisórios e nos seus resultados, conferindo legitimidade especialmente à atuação jurisdicional, é observado em diversos elementos da Constituição Federal Brasileira de 1988. Essa tendência se deve à conjuntura de protagonismo da sociedade civil na vida política à época de implantação da assembléia constituinte.

Nessa perspectiva, Barroso (2008) pontua que a sociedade civil que vivenciou o processo de elaboração da Constituição encontrava-se receosa ante o autoritarismo ainda recente, de modo que o novo texto constitucional marcara a recuperação das liberdades políticas. Pois veja-se:

A Constituição de 1988 é o símbolo maior de uma história de sucesso: a transição de um Estado autoritário, intolerante e muitas vezes violento para um Estado democrático de direito. Sob sua vigência, realizaram-se cinco eleições presidenciais, por voto direto, secreto e universal, com debate público amplo, participação popular e alternância de partidos políticos no poder. Mais que tudo, a Constituição assegurou ao país duas décadas de estabilidade institucional. E não foram tempos banais. Ao longo desse período, diversos episódios deflagraram crises que, em outros tempos, dificilmente teriam deixado de levar à ruptura institucional (BARROSO, 2008, p. 16).

Popularmente conhecida como Constituição Cidadã, o documento marca a passagem do regime militar para o regime civil mediante instrumentos que permitiram a atuação direta do cidadão no sistema de justiça, como por exemplo, a ação civil pública e ação popular, bem como o alargamento dos direitos políticos consubstanciado no sufrágio universal, liberdade de expressão, associação e reunião, entre outros.

Tratando especialmente sobre a co-participação cidadã na função judiciária, a Constituição de 1988 trouxe importantes inovações, alargando o rol de possibilidades que instrumentalizam tal intervenção. Esse raciocínio é observado especialmente no controle de constitucionalidade, sistema de validação das normas jurídicas consoante o texto constitucional.

Nessa discussão, observa-se a inclusão de novos atores entre o rol de legitimados para propor as ações do controle de constitucionalidade brasileiro, a exemplo de partidos políticos, entidades de classe e confederações sindicais, conforme o disposto no art. 103, VII e VIII, além da instituição da figura do amicus curiae, instrumento de participação cidadã em decisões de grande repercussão social proferidas pelas cortes constitucionais. Barroso destaca que:

Assim, o Supremo Tribunal Federal ou outros órgãos judiciais têm dado a última palavra em temas envolvendo separação de Poderes, direitos fundamentais, 
políticas públicas, constitucionalidade de planos econômicos, preservação ambiental, demarcação de terras indígenas e mesmo em questões do dia a dia. Não é difícil ilustrar a tese. Inúmeros programas de governo ou decisões políticas importantes, veiculadas, inclusive, por via de emendas à Constituição, tiveram sua deliberação definitiva em ações perante o Supremo Tribunal Federal (BARROSO, 2008, p. 42).

Esses mecanismos de interação entre sociedade civil e Poder Judiciário devem ser interpretados levando-se em consideração uma conjuntura política que ressignificou profundamente a natureza do referido poder e de suas funções. Assumindo uma posição de centralidade no desenho institucional brasileiro, o Judiciário tornou-se gradativamente um dos protagonistas da vida política, como bem alertou Barboza (2003).

Nessa discussão, Barroso (2008) acrescenta que, ao contrário do que ocorria antes desse novo cenário, o Poder Judiciário implantado nos últimos vinte anos já não passa despercebido ou visto com distanciamento, haja vista a ascensão que se deve à reconstitucionalização do país através da recuperação das liberdades, assunção de um papel político pelo Judiciário e aumento da demanda por justiça na sociedade brasileira.

De acordo com o referido autor, todas essas transformações se deram à luz de sensíveis reestruturações nas teorias constitucionais quanto ao influxo da Constituição sobre a transformação da realidade fática e quanto à percepção dos papéis jurisdicionais no Brasil, o que ocorreu sob influência de movimentos históricos, políticos e doutrinários nacionais e internacionais.

Nessa discussão, observou-se a solidificação de um constitucionalismo inédito pautado na atribuição de força normativa às normas constitucionais, movimento que implicou na imposição de novos paradigmas como a autonomia plena do direito constitucional enquanto disciplina científica e ascensão institucional do Poder Judiciário no Brasil.

Paralelamente a essas doutrinas que subsidiaram ricamente a releitura e expansão das funções judirisdicionais, a doutrina constitucional brasileira também experimentou a emergência de teorias que consolidaram a necessidade institucional de participação cidadã na interpretação do texto constitucional. Barroso destaca que:

Na prática, em todas as hipóteses em que a Constituição tenha criado direitos subjetivos - políticos, individuais, sociais ou difusos - são eles, como regra, direta e imediatamente exigíveis, do Poder Público ou do particular, por via das ações constitucionais e infraconstitucionais contempladas no ordenamento jurídico. $\mathrm{O}$ Poder Judiciário, como consequiência, passa a ter atuação decisiva na realização da Constituição. A doutrina da efetividade serviu-se, como se registrou acima, de uma metodologia positivista: direito constitucional é norma; e de um critério formal para estabelecer a exigibilidade de determinados direitos: se está na Constituição é para ser cumprido. Nos dias que correm, tornou-se necessária a sua 
convivência com novas formulações doutrinárias, de base póspositivista, como a teoria dos princípios, as colisões de direitos fundamentais, a ponderação e o mínimo existencial (BARROSO, 2008, p. 50).

Nessa discussão, Mendes (2008) pontua que tais contribuições se revelaram inestimáveis para o adensamento dos estudos jurídicos brasileiros, chamando a atenção para a doutrina de Peter Häberle, constitucionalista alemão, que defendeu a inclusão do maior número de cidadãos e grupos sociais nos processos de interpretação do texto constitucional.

Tal propósito, destinado a alargar o círculo de intérpretes da Lei Fundamental além das autoridades públicas, associou-se na doutrina ao conceito de "sociedade aberta dos intérpretes da Constituição". Nesse sentido, Mendes (2008) observa as repercussões desse novo modelo jurídico no controle de constitucionalidade brasileiro:

A influência do professor Häberle também pode ser notada no âmbito do Supremo Tribunal brasileiro. Nesse sentido, em julgamento deste tribunal, o voto do eminente Ministro Celso de Mello em questão de ordem na ADIn n ${ }^{\circ} 2.777$, em novembro de 2003, afirmou a possibilidade da sustentação oral de terceiros admitidos no processo de ação direta de inconstitucionalidade, na qualidade de amicus curiae. Sua argumentação foi inteiramente compatível com a orientação de Peter Häberle que "não só defende a existência de instrumentos de defesa da minoria, como também propõe uma abertura hermenêutica que possibilite a esta minoria o oferecimento de 'alternativas' para a interpretação constitucional". Da mesma forma, semelhante influência ocorre no âmbito legislativo. Assim, a Lei no 9.868/99 consagrou a figura do amicus curiae, conferindo uma abertura pluralista ao processo brasileiro de interpretação constitucional, no sentido referido por Peter Häberle (MENDES, 2008, p. 4).

Colocadas essas condições indispensáveis para participação dos cidadãos nas decisões jurisdicionais, poder-se-ia pensar que o processo de judicialização das questões políticas, já discutido em tópico anterior, relaciona-se principalmente com a atuação dos cidadãos na arena pública e com a finalidade de dar resposta aos seus anseios.

No entanto, essa percepção revela-se equivocada à medida que se observa uma significativa distância entre o poder judiciário o povo, bem como a fragilidade dos laços entre esses. Nessa discussão, Cardoso (2009) registra as principais dificuldades para interação entre cidadãos e Poder Judiciário não obstante o contexto de judicialização, observando que as raízes desses obstáculos encontram-se na raiz da tradição judiciária brasileira.

Esse modelo jurisdicional, observado em toda a cultura latino-americana e marcado pela complexidade organizacional herdada das tradições espanholas e portuguesas, ainda se revela muito mais compatível com a preservação de interesses mercantilistas do que com a cidadania propriamente dita (CARDOSO, 2009). 
Aprofundando com precisão os termos dessa discussão sobre as raízes do Judiciário brasileiro e sua hostilidade ante o conceito de cidadania, Koerner (1998) tece interessantes esclarecimentos com o objetivo de demonstrar como o poder judiciário passou da condição de senhor de escravos para cidadão ao longo da história política do país.

De acordo com o autor, todas as instituições brasileiras foram afetadas pela escravidão e o Poder Judiciário não escapou è regra, servindo de apoio dessa estrutura produtiva desde o seu surgimento através de práticas e discursos. Atualmente, a manutenção da exclusão social acontece sob a forma de barreiras que obstaculizam as iguais oportunidades de acesso dos cidadãos à justiça.

Listando os principais problemas de acesso à justiça, Pastor (2006) observa que esses não se manifestam de igual modo e intensidade em todos os países, mas tem em comum o fato de se apresentarem sob a forma de falta de transparência, corrupção, déficit de competência profissional e mediante barreiras especialmente impostas às pessoas menos desfavorecidas.

Voltando a atenção para essas dificuldades de acesso cidadão ao Poder Judiciário, fenômeno observado em toda América Latina, a Costa Rica elaborou um documento no qual é possível identificar a relevância dessa participação no bojo do processo democrático, que deve assegurar o acesso direto e responsável nos processos decisórios e na execução de políticas públicas.

No documento, entende-se ainda que esse acesso deve ser baseado na transparência, distanciamento de interesses pessoais e controle da função jurisdicional, intervenção que não deve se considerar-se como um fim, mas meio de aperfeiçoamento da tutela jurisdicional.

Observa ainda como principais dificuldades externas de acesso ao Poder Judiciário a consciência cidadã insuficiente sobre as dimensões da participação popular por conta de uma formação deficiente nesse sentido além de uma percepção equivocada da independência do judiciário, entendida no senso comum e nas instituições como distanciamento da sociedade.

Identificando as principais relações mantidas entre judicialização e cidadania, Carvalho (2004) pontua que essa é condição extremamente necessária para a emergência daquela, haja vista a inviabilidade de expansão do poder judiciário em países autoritários. No entanto, essa causa insuficiente para a consolidação da judicialização, especialmente no Brasil, onde existe um significativo distanciamento entre o povo e os juízes, apesar do aprofundamento democrático.

O autor acrescenta ainda que a judicialização é um fenômeno nutrido especialmente pelos interesses econômicos e sociais dominantes, capazes de conformar a natureza do processo 
político, o que pode ser constatado até mesmo na expansão dos direitos, mais atribuída à organização das lutas sociais e dos grupos de interesse do que ao altruísmo das autoridades ante os clamores populares.

Dessa forma, o uso dos tribunais pelos grupos de interesse, como forma de concretizar suas pretensões através dos mecanismos jurídicos, e pela oposição, como forma de obstaculizar as alterações constitucionais legitimadas pelas maiorias, constituem o elemento central do processo de judicialização, em detrimento do fator cidadania.

\section{RELAÇÕES INTERSUBJETIVAS ENTRE CIDADÃOS E INSTITUIÇÕES EM UMA CONJUNTURA DE JUDICIALIZAÇÃO DA POLÍTICA}

No contexto latino americano vivenciados nas últimas décadas observa-se o agravamento de problemas estruturais existentes desde o período de colonização, como a pobreza, violência, corrupção e discriminação, que repercutem atualmente na configuração das instituiçõos jurídicas e políticas.

Nessa discussão, Cardoso (2009) afirma a importância da efetividade das instituições para o seu reconhecimento e identidade junto aos cidadãos, que encontram formas de renovação e aperfeiçoamento dessas quando são estáveis. Por outro lado, quando essas não existem ou são frágeis, a falta de confiança, os comportamentos predatórios e a busca de respostas imediatas para os problemas sociais, econômicos e morais tendem a se acumular.

Essas dificuldades, por sua vez, interferem na percepção que os cidadãos nutrem sobre a própria natureza da democracia, acesso à justiça e seu papel no aperfeiçoamento desses. Dessa forma, a desconfiança nas instituições é observada como um problema de destaque atrelado ao conceito de cidadania.

Nessa discussão, pesquisa empírica realizada por Moises e Carneiro (2008) investigou as implicâncias do funcionamento razoável das instituições sobre o sentimento de reconhecimento alimentado dentro dos cidadãos, indicando que a justificação daquelas ocorre à proporção que atuam com imparcialidade, probidade e promoção da igualdade.

Desse modo, a legitimação plena das instituições junto ao povo, condicionada aos resultados apresentados perante este, irradia consequências importantes como a motivação das pessoas para o exercício de deveres legais e cívicos imprescindíveis ao desenvolvimento democrático. 
Aprofundando melhor a discussão relativa à desconfiança dos cidadãos nas instituições, Bobbio (1986) pontua que esse fenômeno de apatia é observado até mesmo nas sociedades em que o sistema democrático encontra-se mais consolidado.

De acordo com o autor, o problema tem como uma das causas principais e negação do indivíduo enquanto centro dos processos hermenêuticos e decisórios, haja vista a fragmentação do povo em grupos de interesses, que são os efetivos protagonistas do espaço público (BOBBIO,1986).

Investigando a relação entre os cidadãos latino americanos e as instituições sociais, jurídicas e políticas, procedeu-se a um levantamento qualitativo, entre maio de junho de 2016, mediante a realização de entrevistas com amostras representativas de $100 \%$ das populações consideradas, tendo a Corporação Latinobarómetro (Santiago de Chile) ${ }^{4}$ como responsável pelos dados.

Entre as principais conclusões do estudo, destaca-se a ausência de credibilidade das instituições democráticas e do sistema de justiça ante o aumento das demandas jurisdicionais e prevalência de problemas como violência, corrupção, desigualdade e consequentemente atraso econômico e democrático.

Quanto ao apoio às instituições democráticas, a pesquisa observou que a previsão de instrumentos constitucionais que assegurem a participação política dos cidadãos é insuficiente, havendo necessidade de maior garantia de direitos e políticas sociais, fatores de motivação popular.

\footnotetext{
${ }^{4}$ A Corporação Latinobarômetro é entidadesem fins lucrativos com sede em Santiago do Chile. Atualmente conta com o primeiro banco de dados opinião em espanhol, no Hemisfério Sul e na América Latina, sistema operado por JD Sistema em Madrid.
} 


\section{APOYO A LA DEMOCRACIA TOTAL POR PAIS 2016}

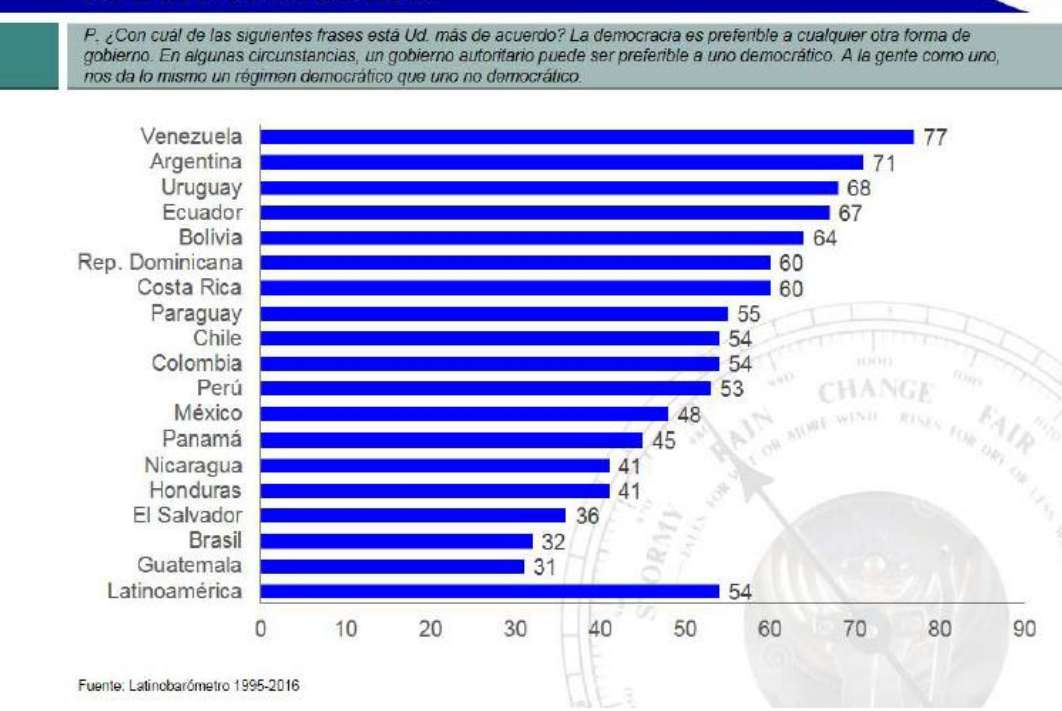

Conforme os dados do gráfico acima, o Brasil está entre os países em que se registram fortes quedas do apoio à democracia, ficando à frente apenas da Guatemala. Esses dados, correspondentes ao ano de 2016, permitem observar o desencanto com os governos e instituições democráticas ao mesmo tempo em que o país presencia o aumento significativo da interferência do Poder Judiciário na vida pública, conforme já foi explorado em seções anteriores.

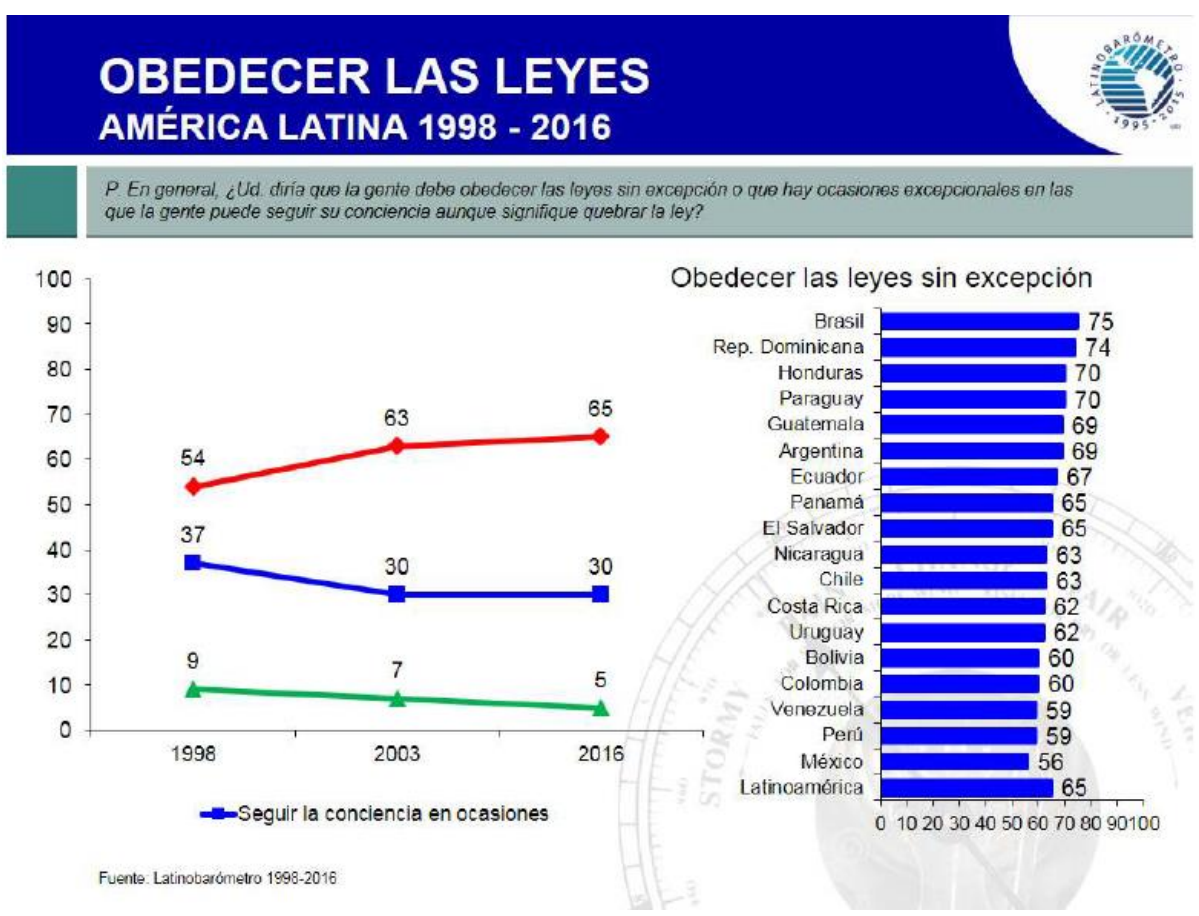

Fonte: Latinobarómetro 1998-2016 
Quanto à necessidade de obedecer a leis, a pesquisa apontou uma predisposição dos cidadãos em todos os países considerados, onde os ordenamentos jurídicos ainda possuem um caráter simbólico, não obstante as dificuldade em sua concretização. Dessa forma, as pessoas concordam majoritariamente que devem obedecer as leis.

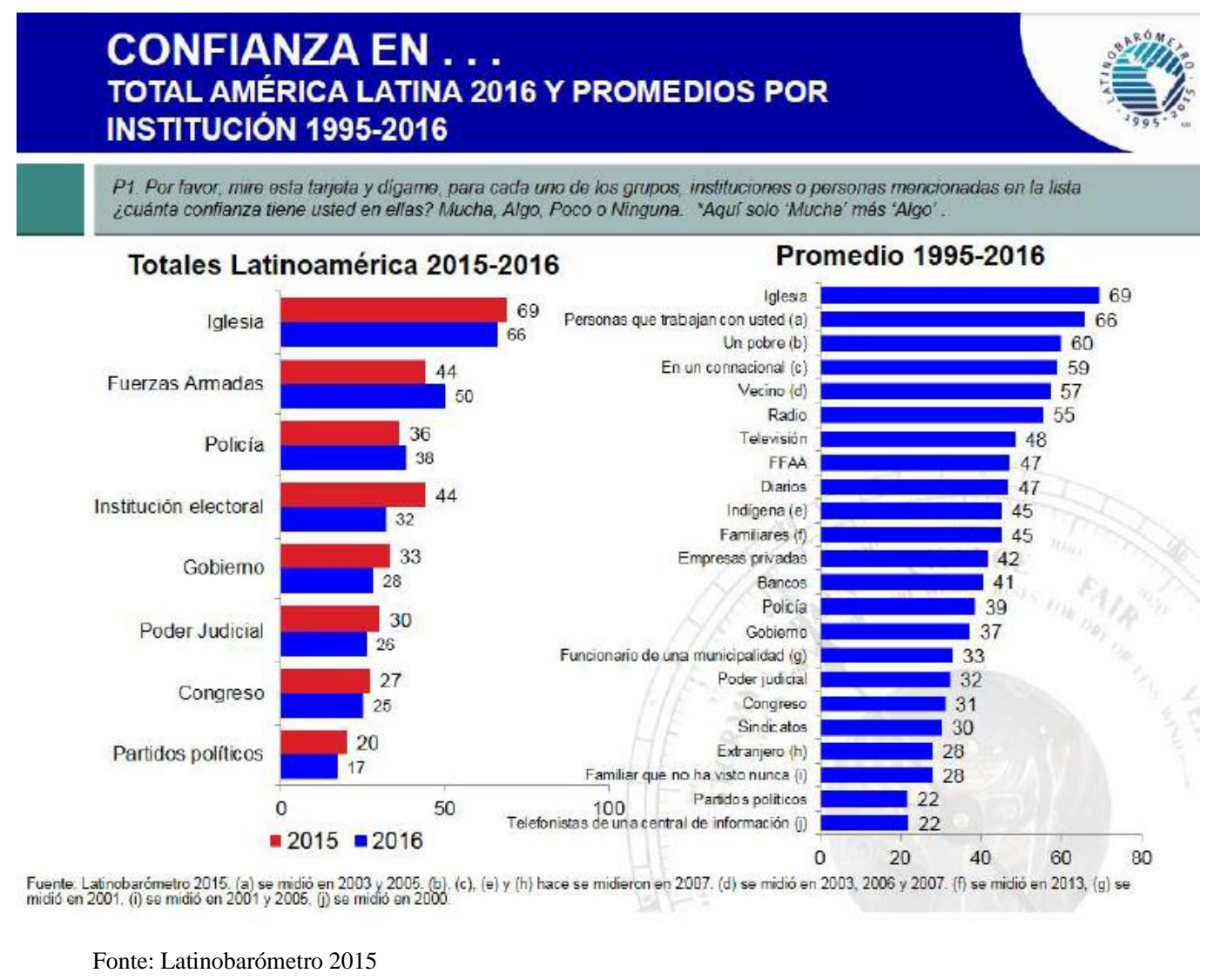

Mensurando a confiança dos cidadãos nas instituições, a pesquisa realizada pela corporação Latinobarómetro apontou resultados preocupantes, indicando que essa variável declinou significativamente nos últimos anos, exceto no caso das forças armadas e policiais, instituições em que a confiança não caiu drasticamente.

Conforme o apontado pelo estudo, o Judiciário, Congresso Nacional e partidos políticos são atualmente as instituições menos creditadas pelos cidadãos de um modo geral. Contextualizando esses dados com o processo de judicialização experimentado especialmente pela América Latina nas últimas décadas, observa-se uma importante contradição, qual seja, a expansão absurda das funções jurisdicionais acompanhada pelo descrédito do poder judiciário. 


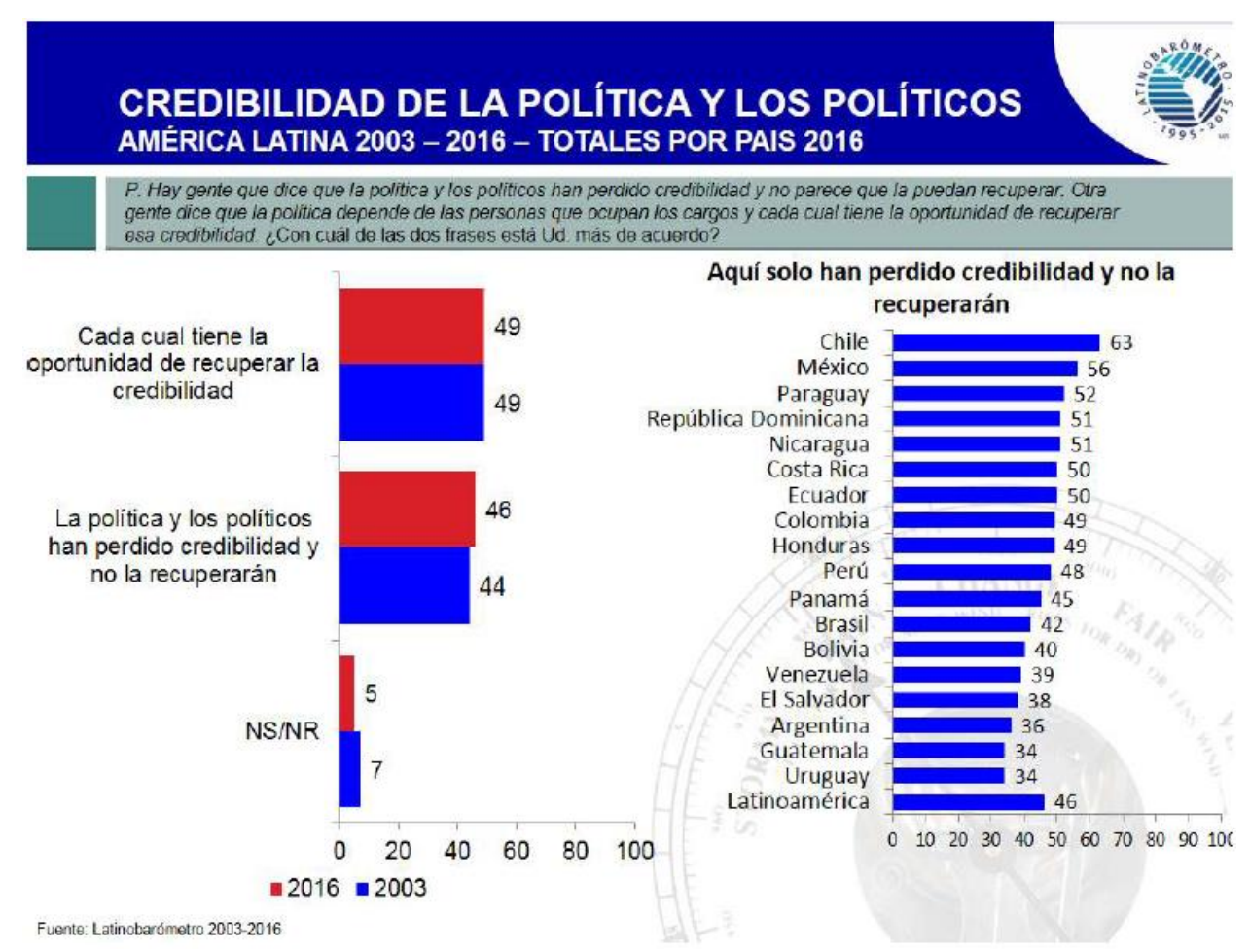

Fonte: Latinobarómetro 2003-2016

Observando a credibilidade da política e dos partidos, a pesquisa concluiu que houve uma diminuição generalizada dessa variável nos países considerados, haja vista o aumento da corrupção como principal problema dos países, o que impede o desenvolvimento satisfatório dos processos democráticos e aprovação pelos cidadãos.

Nessa discussão, destaca-se o elevado número de cidadãos que acreditam ser impossível restaurar a credibilidade da política, percentual de $40 \%$ na realidade brasileira. Mais uma vez contextualizado com o processo de judicialização, observam-se conclusões importantes no sentido de que os poderes Legislativo e Executivo estão em colapso, contexto em que o Poder Judiciário assume parte dessas funções.

Diante de todo o exposto, é possível concluir que a relação entre cidadãos e ordem política é alimentada por percepções desse quanto à sua correta atuação, implicando em apoio e identificação, em caso positivo e em distanciamento, em caso negativo. Na experiência democrática brasileira, a pesquisa empírica analisada apontou duas percepções distintas por parte dos cidadãos.

Se, por um lado, os cidadãos entrevistados acreditam majoritariamente no sistema democrático enquanto melhor forma de distribuição de poder entre governantes e governados, assumindo a obrigação de obedecer a leis, por outro lado, demonstram ausência de confiança nas instituições e baixa credibilidade da política dessas. 


\section{CONCLUSÕES}

Caracterizada pela atuação jurisdicional em matérias de cunho claramente político, bem como o exercício de funções pelo poder Judiciário em limites que correspondem aos demais poderes, a judicialialização da política tem ocorrido associada a diversas variáveis, observadas, cujo modo e intensidade se diferenciam conforme as peculiaridades de cada país

Entre as principais condições políticas que embasaram o aparecimento desse fenômeno, observa-se o déficit democrático oriundo da crise de legitimidade política, implantação dos sistemas democráticos em toda América Latina, emergência de práticas cidadãs de enfrentamento à corrupção, a catalogação de variadas categorias de direitos nas Constituições modernas, entre outros.

No presente trabalho, observou-se que o processo de judicialização mantém relações diretas com a descrença popular ante a efetividade política dos poderes Legislativo e Executivo, havendo, portanto a percepção popular no sentido de que o poder Judiciário é essencialmente a instância mais apropriada para a resolução de demandas políticas de alcance público e particular.

No entanto, demonstrou-se que esse raciocínio revela suas falhas à medida em que ainda observa-se uma considerável distância entre o povo e o poder judiciário, bem como a fragilidade dos laços mantidos entre esses. Essas dificuldades são alimentadas por déficits estruturais, que enraizados na cultura latino americana desde épocas remotas, se mantém nas instituições não obstante as transformações experimentadas por essas.

Observa-se também que a cidadania não constitui o eixo principal do processo de judicialização, haja vista a centralidade dos grupos de interesse e o uso dos tribunais pela oposição como principais causas do aumento da litigância junto às cortes constitucionais.

Diante de todo o exposto, é possível concluir que a relação entre cidadãos e ordem política é alimentada por percepções desse quanto à sua correta atuação, implicando em apoio e identificação, em caso positivo e em distanciamento, em caso negativo. Na experiência democrática brasileira, a pesquisa empírica analisada apontou duas percepções distintas por parte dos cidadãos.

Se, por um lado, os cidadãos entrevistados acreditam majoritariamente no sistema democrático enquanto melhor forma de distribuição de poder entre governantes e governados, 
assumindo a obrigação de obedecer a leis, por outro lado, demonstram ausência de confiança nas instituições e baixa credibilidade da política dessas.

Assim, observou-se que o processo de judicialização, irradiando nas dimensões política, cultural e institucional, não foi acompanhado por um contentamento significativo dos cidadãos ante a atuação do poder judiciário e das instituições de um modo geral, consoante as conclusões do estudo empírico realizado pela Fundação Latinobarômetro.

Ao mesmo tempo, considera-se que os obstáculos do acesso à justiça persistem após a implantação da Constituição de 1988, que criou diversos mecanismos para instrumentalizar esse direito. Desse modo, conclui-se que, muito embora detenham algum peso entre as condições que alimentam o processo de judicialização, o aprofundamento da práticas cidadãs, bem como o acesso razoável às instituições não são elementos decisivos para a compreensão do fenômeno em estudo.

\section{REFERENCIAS}

BARBOSA, Luís Felipe Andrade. FERNANDEZ, Michelle. Políticas Públicas Sociais no Brasil: estudos sobre o papel do Judiciário na promoção de direitos de cidadania. Revista Cidadania e Direitos Humanos, Caruaru, v. 1, n. 1, p. 1-19, jul./dez. 2015. Disponível em: < http://repositorio.asces.edu.br/bitstream/123456789/85/1/luis\%20felipe.pdf >. Acesso em 20 mai 2017.

BARBOZA, Estefênia Maria de Queiroz. Judicialização da política: um fenômeno jurídico ou político. A\&C Revista de Direito Administrativo \& Constitucional. ano 3, n. 11, jan./mar. 2003. Belo Horizonte: Fórum, 2003. Disponível em:

<http://www.revistaaec.com/index.php/revistaaec/article/view/290/143>. Acesso em 10 ago 2019.

BARROSO, Luís Roberto. Vinte anos da constituição brasileira de 1988: O estado a que chegamos. Cadernos da Escola do Direito. v. 1, n. 8 (2008). Disponível em:< http://revistas.unibrasil.com.br/cadernosdireito/index.php/direito/article/view/699/655. Acesso em 24 mai 2017.

BOBBIO, Norberto. $O$ futuro da democracia (uma defesa das regras do jogo). Trad. Marco Aurélio Nogueira. Rio de Janeiro, Paz e Terra, 1986.

BRANDÃO, Rodrigo. A Judicialização da Política: Teorias, condições e o caso brasileiro. rda - revista de Direito Administrativo, Rio de Janeiro, v. 263, p. 175-220, maio/ago. 2013. Disponível em: < http://bibliotecadigital.fgv.br/ojs/index.php/rda/article/view/10648>. Acesso em 15 mai 2017.

CARDOSO, Fernando Henrique. FOXLEY, Alejandro. América Latina: governabilidade, globalização e políticas econômicas para além da crise. São Paulo: Campus, 2009. 
CARVALHO, Ernani Rodrigues de. Em busca da judicialização da política no Brasil: apontamentos para uma nova abordagem. Rev. Sociol. Polit. [online]. 2004, n.23, pp.127139. ISSN 1678-9873. http://dx.doi.org/10.1590/S0104-44782004000200011.

CORPORACIÓN LATINOBARÓMETRO. "El declive de la democracia-

Latinobarometro 2016". Disponível em: http://www.latinobarometro.org/latNewsShow.jsp. Acesso em: $17 \mathrm{dez} 2016$.

COSTA RICA. PODER JUDICIAL. Política de Participación Ciudadana en El Poder Judicial 2016. Disponível em: < https://www.poderjudicial.go.cr/participacionciudadana/images/documentos/ppc.pdf>. Acesso em 20 mai 2017. FONTOURA, Carolina Leite Amaral. Judicialização da política no âmbito do controle orçamentário e a controladoria de políticas públicas. Revista Questio Iuris, vol. 08, n. 03. Rio de Janeiro, 2015, p. 1421-1440. Disponível em: <https://www.epublicacoes.uerj.br/index.php/quaestioiuris/article/view/18830/14168>. Acesso em 17 jun 2019

GUSTIN, Miracy Barbosa de Sousa. DIAS, Maria Tereza Fonseca. (Re) pensando a pesquisa jurídica: teoria e prática. Belo Horizonte: Del Rey, 2002.

LÜDKE, M.; ANDRÉ, M.E.D.A. Pesquisa em educação: abordagens qualitativas. São Paulo, EPU, 1986.

KOERNER, Andrei. Judiciário e Cidadadania na Constituição da República Brasileira. São Paulo: DCP-USP/Hucitec 1998.

MACIEL, D; KOERNER, A. 2002. Sentidos da judicialização da política: duas análises. Luz Nova, São Paulo, n.57, p. 113-133. Disponível em: <

http://www.scielo.br/pdf/ln/n57/a06n57.pdf>. Acesso em 15 mai 2017.

MENDES, Gilmar. Homenagem à doutrina de Peter Häberle e sua influência no Brasil, 2008. Disponível

em:<http://www.stf.jus.br/repositorio/cms/portalStfInternacional/portalStfAgenda_pt_br/anex o/Homenagem_a_Peter_Haberle_Pronunciamento_3_1.pdf $>$.Acesso em28 abr 2017.

MOISÉS, José Álvaro; CARNEIRO, Gabriela Piquet. Democracia, desconfiança política e insatisfação com o regime - o caso do Brasil. Opin.

Publica vol.14 no.1 Campinas June 2008.

MOTTA, Luiz Eduardo. Judicialização da política e representação funcional no Brasil contemporâneo: uma ameaça à soberania. Revista Questio Iuris, vol. 05, n. 01. Rio de Janeiro, 2012, p. 256-285. Disponível em: < https://www.e-

publicacoes.uerj.br/index.php/quaestioiuris/article/view/9878/7740>. Acesso em 12 de jun 2019.

PASTOR, Santos. ROBLEDO, Jesús. Experiência y Buenas Practicas em gestion de calidad de la Justicia. Universidad Complutense de Madrid y Observatorio Justicia y Empresa, 2006. . Disponível em: < https://e- 
archivo.uc3m.es/bitstream/handle/10016/11116/experiencias_arnaiz_2007.pdf>. Acesso em 20 mai.

RAMOS, Edith Maria Barbosa. DINIZ, Isadora Moraes. Os partidos políticos e os tribunais constitucionais: quem está dirimindo as questões políticas? Revista do Curso de Direito. V. 04. N. 08. Jun/dez. São Luís, 2014. Disponível em:

<http://www.periodicoseletronicos.ufma.br/index.php/rcursodedireito/article/view/5254/3192>. Acesso em: 13 mar 2019.

ROLLÓN, Marisa Ramos. Sistemas Judiciales y Democracia em Centroamérica: La perspectiva de los juices, 2005. Documentos CIDOB, n.8. (Seria América Latina).

Trabalho recebido em 14 de agosto de 2019

Aceito em 05 de dezembro de 2020 